\title{
Energy consumption and real GDP: Panel co-integration and causality tests for sub-Saharan African countries
}

\author{
Babajide Fowowe \\ University of Ibadan
}

\begin{abstract}
This paper investigates the causal relationship between energy consumption and real GDP in 14 Sub-Saharan African countries over the period 1971-2004. The results of panel co-integration tests showed that energy consumption and real GDP do not have a stable long-run equilibrium relationship. We find that for all members of the panel, there is homogenous causality from energy consumption to real GDP and vice versa. This bi-directional causality supports the feedback hypothesis.
\end{abstract}

Keywords: energy consumption, Sub-Sahara Africa, panel co-integration, real GDP

\section{Introduction}

The causal relationship between energy and real GDP has attracted attention for almost three decades. Theoretically, the importance of energy to output, and of output to energy has been established. On one hand, energy has been identified as an important input in the production process and some authors have advocated the inclusion of energy in the production function alongside other factors such as land, labour and capital (Ebohon, 1996; Chontanawat et al., 2006; Alam, 2006), while some other authors see energy as enhancing the productivity of other factors of production (Cheng and Lai, 1997). In addition to this, energy sector development is essential for economic development and improved quality of energy services are expected to increase economic productivity (Toman and Jemelkova, 2003). The improvements in economic productivity can then lead to increased wages and this helps in reducing poverty (International Energy Agency, 2002). Thus, energy sector development can lead to both economic development and poverty reduction.

On the other hand, as the economy grows the consumption of energy increases. Economic development enhances energy sector development because it involves a transition from less efficient energy sources such as commercial fossil fuels to more efficient sources such as electricity (Toman and Jemelkova, 2003).

Following from the above discussion, energy development can cause economic growth and also, economic growth can cause energy development. Increased interest has been placed on the nature of the relationship between energy and economic development. A major reason for such interest in the energy-economic development nexus is because knowing the direction of causality will help in shaping environmental and energy policies. If energy causes economic development, this implies energy-dependence and low or falling energy would adversely affect income and energy conservation policies would lead to a fall in output (Lee, 2005; Akinlo, 2008; Apergis and Payne, 2009). This has been referred to in the literature as the growth hypothesis. On the other hand, if causality is found to run from economic development to ener$\mathrm{gy}$, this supports the conservation hypothesis and such an economy is less energy-dependent and energy conservation policies can be implemented with little or no adverse effects on income (Jumbe, 2004; Lee, 2005). A similar conclusion is reached if no causal relationship is found between energy and economic development and energy conservation policies can be implemented without having an adverse effect on output. This is the neutrality hypothesis. Finally, the feedback hypothesis is supported if bi-directional causality is found, in which case economic development and energy consumption are complementary and energy policies should be geared towards improving energy consumption 
efficiency so as not to adversely affect income (Apergis and Payne, 2009).

This paper contributes to the literature on the causal relationship between energy and real GDP and improves on previous empirical research on African countries by using panel data co-integration and causality tests. Previous studies on the energyGDP relationship in African countries have made use of single country time series unit root and cointegration tests which have been shown to have low power (Maddala and Wu, 1999). Using data for 14 countries in Sub-Saharan Africa, we improve on existing studies on African countries in 2 main ways. Firstly, we make use of panel unit root and co-integration tests and thereby address the low power criticisms of single country unit root and co-integration tests (Maddala and Wu, 1999). Secondly, by using a panel analysis, we exploit both the time-series and cross-section dimension of our data thereby increasing the number of observations and degrees of freedom, thus improving the efficiency of causality tests (Hurlin and Venet, 2001).

\section{Literature review}

The exact direction of causality between energy and economic development has attracted considerable attention. These studies can be broadly divided into two; studies that employed time series econometric techniques and studies that employed panel data econometric techniques. These two groups of studies are discussed. What can be observed from these studies is that there is a diverse array of results about the direction of causality between energy and GDP and we could not find any broad consensus in the literature. A possible explanation for such diverse results is that there are many institutional, structural and policy differences among countries. Also, there are many methodological differences which play a major role on how the econometric tests are conducted and ultimately affect the results (Masih and Masih, 1996).

\subsection{Studies based on time series econometrics}

Cheng and Lai (1997) employed data for Taiwan over the period 1955 - 1993 to examine the causality between energy consumption and economic activity. The authors measured economic activity with real GDP and employment. Co-integration tests showed that co-integration does not exist among the variables and so there is no stable longrun relationship between economic activity and energy consumption in Taiwan. The results of granger causality tests showed unidirectional causality from energy consumption to employment and also unidirectional causality from economic growth to energy consumption. The authors conclude that the results support the conservation hypothesis.
Masih and Masih (1996) examined the causal relationship between energy consumption and GDP in Asian countries. The authors used data ranging broadly over the period 1955-1990 for India, Pakistan, Malaysia, Singapore, Indonesia, and the Philippines and conducted co-integration tests which showed that energy consumption and GNP are co-integrated in India, Pakistan, and Indonesia. There was no evidence of co-integration in Malaysia, Singapore and the Philippines. The results of causality tests showed that there is no causality between energy consumption and GDP in Malaysia, Singapore and the Philippines. The results showed unidirectional causality from GDP to energy consumption in Indonesia, unidirectional causality from energy consumption to GDP in India, and bidirectional causality in Pakistan. The authors attribute the divergent results to the fact the countries are implementing different energy-growth policies.

The study by Chontanawat et al. (2006) used data for 108 countries to empirically examine causality between energy consumption and GDP. The sample consisted of 78 non-OECD and 30 OECD countries. For the non-OECD countries, the authors employed data over the period 1971 - 2000 while for the OECD countries, data was used over the period 1960 - 2000. Taking all countries together, the results of causality tests showed that there is unidirectional causality from GDP to energy consumption in 20 countries while unidirectional causality runs the other way in 23 countries. There was bidirectional causality in 34 countries while there was no causality in 31 countries. Breaking the results down showed that there was a higher prevalence of causality in OECD than non-OECD countries. The authors explanation for this finding was that less developed countries are predominantly agrarianbased and thus less energy dependent.

Oh and Lee (2004) examined the energy-GDP causal relationship using data for Korea over the period 1970-1999. Apart from energy consumption and GDP, the authors also included variables measuring capital and labour in their causality tests. The results showed unidirectional causality from energy consumption to GDP in the short-run and bidirectional causality in the long-run.

There are a few studies on African countries which include Ebohon (1996), Jumbe (2004), Wolde-Rufael (2005, 2009).

The study by Ebohon (1996) examined the energy-GDP causal relationship for Nigeria and Tanzania. The author used data over the period 1960-1984 for Nigeria and 1960-1981 for Tanzania. The authors used 2 different measures of economic growth: GDP and GNP. The results of Granger causality tests found bi-directional causality between energy consumption and economic growth in Tanzania and Nigeria, thus supporting the 
feedback hypothesis that there is a complementary relationship between energy and growth.

Wolde-Rufael (2005) used data for 19 African countries over the period 1971-2001 to investigate the causal relationship between energy and GDP. Departing from previous studies, the author used the bounds test for co-integration and then employed the Toda and Yamamoto causality test. The bounds co-integration test showed the existence of stable long-run relationship between energy and growth in 8 countries while there was no cointegration in 11 countries. The results of causality tests showed that causality runs from economic growth to energy consumption in 5 countries (Algeria, Democratic Republic of Congo, Egypt, Ghana, and Cote d'Ivoire) while energy causes economic growth in 3 countries (Cameroon, Morocco, and Nigeria). There was bi-directional causality in 2 countries (Gabon and Zambia) while no causality was found in 9 countries (Benin, Congo Republic, Kenya, Senegal, South Africa, Sudan, Togo, Tunisia and Zimbabwe).

Akinlo (2008) also employed the bounds cointegration test to examine the long-run relationship between energy consumption and economic growth in 11 Sub-Saharan African countries: Cameroon, Cote d'Ivoire, Congo, Gambia, Ghana, Kenya, Nigeria, Senegal, Sudan, Togo, and Zimbabwe. The author employed a multivariate framework which included energy consumption, GDP, government expenditure, and the consumer price index. The co-integration tests supported cointegration in 7 countries (Cameroon, Cote d' Ivoire, Gambia, Ghana, Senegal, Sudan and Zimbabwe. The granger causality tests showed that economic growth causes energy in 2 countries (Sudan and Zimbabwe). Bi-directional causality was found for 3 countries (Gambia, Ghana and Senegal). For 5 countries (Cameroon, Cote d' Ivoire, Nigeria, Kenya and Togo) no causality was found.

Wolde-Rufael (2009) used data over the period 1971 - 2004 to study the relationship between energy consumption and economic growth in 17 African countries. In addition to GDP and energy consumption, the author included 2 additional variables: real gross capital formation and employment. Causality tests showed that energy consumption causes economic growth in 3 countries (Algeria, Benin and South Africa). They also found that economic growth causes energy in 8 countries (Cote d'Ivoire, Egypt, Morocco, Nigeria, Senegal, Sudan, Tunisia, and Zambia). Bi-directional causality was found in 4 countries (Gabon, Ghana, Togo and Zimbabwe) while no causality was found in Cameroon and Kenya.

\subsection{Studies based on panel data}

Lee (2005) employed panel data techniques to study the causal relationship between energy consumption and GDP in 18 developing countries over the period 1975 - 2001. Panel co-integration tests showed the presence of a long-run relationship between energy and GDP and the causality tests supported the growth hypothesis as unidirectional causality was found from energy consumption to GDP.

Apergis and Payne (2009) examined causality between energy consumption and GDP using panel data techniques for 6 Central American countries: Costa Rica, El Salvador, Guatemala, Honduras, Nicaragua, and Panama. Using data over the period 1980 - 2004, the authors included 2 additional variables in the causality testing framework: real gross fixed capital formation and labour force. The results showed that energy consumption causes economic growth in the panel of Central American countries.

Narayan and Smyth (2008) used data for 7 developed countries over the period $1972-2002$. The authors conducted panel co-integration tests using the ordinary Pedroni panel co-integration tests and panel co-integration tests with structural breaks. While the Pedroni co-integration tests did not reveal any co-integration, the co-integration tests with structural breaks wooed the existence of co-integration and the authors then concluded that the series are co-integrated. The results of long-run causality tests showed that energy consumption causes real GDP in this panel of 7 developed countries, thereby supporting the growth hypothesis.

\section{Methodology}

\subsection{Panel unit root test}

It has been suggested that using panel data unit root tests can increase the low power of unit root tests based on single country time series (Maddala and $\mathrm{Wu}, 1999)$. A number of panel data unit root tests have been proposed such as: Maddala and $\mathrm{Wu}$ (1999), Choi (2001), Levin, Lin and Chu (2002), and Im, Pesaran and Shin (2003). These tests are generally based on the $\mathrm{AR}(1)$ process:

$$
\gamma_{i t}=\mu_{i}+\tau_{i} t+\rho_{i} \gamma_{i t-1}+\varepsilon_{i t}
$$

where $t=1, \ldots, \mathrm{T}$ is the number of periods and $\mathrm{i}=$ $1, \ldots, \mathrm{N}$ is the number of countries. $\tau_{\mathrm{i}}$ is an individual trend, $\mu_{\mathrm{i}}$ is the country specific fixed effect, $\rho_{\mathrm{i}}$ is an autoregressive coefficient, and $\varepsilon_{\text {it }}$ is the error term. There is a unit root in $\gamma_{i t}$ if $\left|\rho_{\mathrm{i}}\right|=1$.

Panel unit root tests are broadly classified into 2 based on their assumptions concerning whether $\rho_{i}$ is constant or varying. The tests that assume that the autoregressive parameter $\rho_{\mathrm{i}}$ is constant across countries (ie. $\rho_{\mathrm{i}}=\rho_{\mathrm{i}}$ ) include Levin et al. (2002) while Maddala and Wu (1999), Choi (2001) and Im et al. (2003) assume that $\rho_{\mathrm{i}}$ varies across countries. The null hypothesis of the 2 types of panel unit root 
tests is the same, that is, there is a unit root in all series. The alternative hypothesis varies depending on whether $\rho_{\mathrm{i}}$ is assumed to be constant or varying. For the tests that assume that $\rho_{\mathrm{i}}$ is constant, the alternative hypothesis is that there is stationarity of all the series. This is represented below:

$$
\begin{aligned}
& \mathrm{H}_{0}: \rho_{\mathrm{i}}=0 \text { for all } \mathrm{i} \\
& \mathrm{H}_{\mathrm{A}}: \rho_{\mathrm{i}}=\rho<0 \text { for all } \mathrm{i} .
\end{aligned}
$$

For the other group of tests that assume that $\rho_{\mathrm{i}}$ varies across countries, the alternative hypothesis is that there are unit roots in some (but not necessarily all) of the series. This is given by:

$$
\begin{aligned}
& \mathrm{H}_{0}: \rho_{\mathrm{i}}=0 \text { for all } \mathrm{i} \\
& \mathrm{H}_{\mathrm{A}}: \rho_{\mathrm{i}}<0 \text { for all } \mathrm{i} .
\end{aligned}
$$

In this paper, we have employed 2 panel unit root tests that have different alternative hypothesis which are the Levin et al. (2002) and Im et al. (2003) tests.

In the Levin et al. test it is assumed that the autoregressive coefficient (which indicates whether or not unit roots are present) is homogenous. Although the autoregressive coefficient is assumed homogenous, the Levin et al. test allows for heterogeneity by allowing fixed effects and country-specific time trends.

The Im et al. (2003) test involves computing the $\mathrm{ADF}$ test for each individual country and the mean of all countries' ADF statistics gives the overall t-test statistic.

\subsection{Panel cointegration test}

The panel co-integration tests in this paper use the tests of Pedroni (1999). The co-integrating equation takes the form:

$$
\gamma_{i t}=\gamma_{i}+\kappa_{i t}+\gamma_{i} \chi_{i t}+\varepsilon_{i t}
$$

For $\mathrm{t}=1, \ldots, \mathrm{T}$ and $\mathrm{i}=1, \ldots, \mathrm{N}$. The fixed effects, $\gamma_{i}$ and slope coefficients $\lambda_{i}$ are allowed to vary across individual countries.

$$
\varepsilon_{i t}=\Psi_{i} \varepsilon_{i t-1}+v_{i t}
$$

where $\Psi_{i}$ is the autoregressive coefficient of the residual $\varepsilon_{\text {it }}$ from equation 2 .

Pedroni (1999) developed seven panel co-integration tests. The first four are within-dimension statistics which are derived by pooling the autoregressive coefficients across the different countries for the unit root tests on the estimated residuals. These four statistics are: panel v-statistic, panel rho-statistic, panel pp-statistic, and panel-ADF-statistic. The within-dimension statistics test the null hypothesis of no co-integration, $\mathrm{H}_{0}: \Psi_{\mathrm{i}}=1$ for all $\mathrm{i}$ against the alternative, $\mathrm{H}_{\mathrm{A}}$ : $\Psi_{\mathrm{i}}=\Psi<1$ for all $\mathrm{i}$. The next three tests are between-dimension statistics and are based on averaging the individually estimated coefficients for each country. The three statistics are: group rhostatistic, group pp-statistic, and group ADF-statistic. The null hypothesis of the between-dimension statistics is given by $\mathrm{H}_{0}: \Psi_{\mathrm{i}}=1$ for all $\mathrm{i}$ and the alternative is $\mathrm{H}_{\mathrm{A}}: \Psi_{\mathrm{i}}<1$ for all i. Pedroni (1999) shows that the panel v-statistic is a one-sided test where large positive values reject the null hypothesis of no co-integration. For the remaining statistics large negative values reject the null hypothesis of no cointegration. We make use of all seven statistics proposed by Pedroni to test for co-integration.

\subsection{Panel causality test}

This study makes use of the panel causality testing framework of Hurlin and Venet (2001). Hurlin and Venet (2001), note that the heterogeneity between countries is an important consideration when conducting analysis with panel data. Such heterogeneity is from two sources: the first source being differences in intercepts of different countries. Such heterogeneity is controlled by using country specific (fixed) effects in the model. The second source of heterogeneity is the case where regression coefficients slopes vary across countries. This kind of heterogeneity is often ignored in the literature and could lead to wrong conclusions about causality. Thus, Hurlin and Venet (2001) develop tests to address this type of heterogeneity.

Hurlin and Venet make use of a panel Granger model where for each individual $\mathrm{i}$ and for all $\mathrm{t}$ in $[1$, T] we have:

$$
y_{i, t}=\sum_{k=1}^{p} \gamma^{(k)} y_{i, t-k}+\sum_{k=0}^{p} \beta_{i}^{(k)} x_{i, t-k}+v_{i, t}
$$

where it is assumed that the autoregressive coefficients $\gamma^{(\mathrm{k})}$ and the regression coefficients slopes $\beta_{\mathrm{i}}{ }^{(\mathrm{k})}$ are constant for all $\mathrm{k}$ in $[1, \mathrm{p}]$. It is also assumed that the autoregressive coefficients are identical for all units while the regression coefficients slopes can vary across individuals. Based on this, Hurlin and Venet propose 4 kinds of causality relationships which take account of the heterogeneity of the underlying processes. The testing procedure is a set of nested tests which makes use of the F-test and rejection of the null hypothesis of the first case involves moving unto the second case and so on, while the testing ends when the null hypothesis for any case is not rejected. The four causality tests are briefly outlined below.

The first case is Homogenous Non Causality (HNC) which implies that no causality relationship exists for any of the individual cross-sections. If the computed F-statistic is significant, the Homogenous Non-Causality Hypothesis is rejected (that is causality exists for at least one member of the panel), and 
we proceed to test the Homogenous Causality Hypothesis. On the other hand, if the HNC Hypothesis is accepted, no causality relationship exists in any member of the panel and the testing process ends there.

The second case is Homogenous Causality $(\mathrm{HC})$ and under this, there are $\mathrm{N}$ causality relationships which implies that causality exists in each individual. If the F-statistic is insignificant, the Homogenous Causality Hypothesis is accepted meaning that causality relationships exist in all members of the panel and further testing is unnecessary. If the $\mathrm{HC}$ Hypothesis is rejected this implies that no causality relationship exists in at least 1 member of the panel and we proceed to the third case.

Rejection of the $\mathrm{HC}$ Hypothesis implies no homogenous causality and we then proceed to the heterogeneity tests to test which of the members of the panel exhibits a causal relationship. The third case is Heterogeneous Causality (HEC) and the implication of this is that causal relationships exist in at least 1 individual, and causality could rise to a maximum of $\mathrm{N}$. The fourth case is Heterogeneous Non Causality (HENC) which implies that for at least 1 individual, and at most $\mathrm{N}-1$ individuals, a causality relationship does not exist. A significant statistic implies rejection of the HENC hypothesis, and so a causality relationship exists for the individual under consideration. The second test consists in testing the joint hypothesis of no causal relationship for a subgroup of individuals in the panel. In this case, the slope coefficients of all lags for the individuals of the subgroups are constrained to zero. If the F-statistic is significant, this implies rejection of the HENC for the sub-group under consideration and concluding that causality exists for this subgroup of panel members.

\section{Data and empirical results}

Annual data over the period 1971 to 2004 for 14 SSA countries has been used in this study1. All data is from the World Development Indicators CD-ROM 2007. Energy consumption is energy use in kilotons of equivalent oil and real GDP is in constant 2000 U.S. dollars. All variables are in natural logarithms.

We first conducted panel unit root tests for all variables and the results are presented in Table 1. The results show that with the exception of the Levin et al. statistic without trend, both variables contain a panel unit root in levels but are stationary

Table 1: Panel unit root tests

\begin{tabular}{lcccc}
\hline Variables & \multicolumn{2}{c}{ Levin et al. } & \multicolumn{2}{c}{ Im et al. } \\
& Without trend & With trend & Without trend & With trend \\
\hline LY & $-2.55^{*}$ & -1.11 & 1.42 & -0.58 \\
& {$[0.0053]$} & {$[0.1330]$} & {$[0.9221]$} & {$[0.2805]$} \\
\hline LEC & $-3.37^{*}$ & -1.17 & 1.26 & -0.29 \\
& {$[0.0004]$} & {$[0.1213]$} & {$[0.8959]$} & {$[0.3880]$} \\
\hline DLY & $-11.49^{*}$ & $-8.81^{*}$ & $-11.67^{*}$ & $-9.85^{*}$ \\
& {$[0.0000]$} & {$[0.0000]$} & {$[0.0000]$} & {$[0.0000]$} \\
\hline DLEC & $-18.65^{*}$ & $-15.32^{*}$ & $-17.88^{*}$ & $-15.22^{*}$ \\
& {$[0.0000]$} & {$[0.0000]$} & {$[0.0000]$} & {$[0.0000]$} \\
\hline
\end{tabular}

Notes:

* Indicates statistical significance at the $1 \%$ level, ** indicates statistical significance at the $5 \%$ level, *** indicates statistical significance at the $10 \%$ level.

Values in [] are p-values. LY=logarithm of real GDP, LEC=logarithm of energy consumption.

Table 2: Panel co-integration test

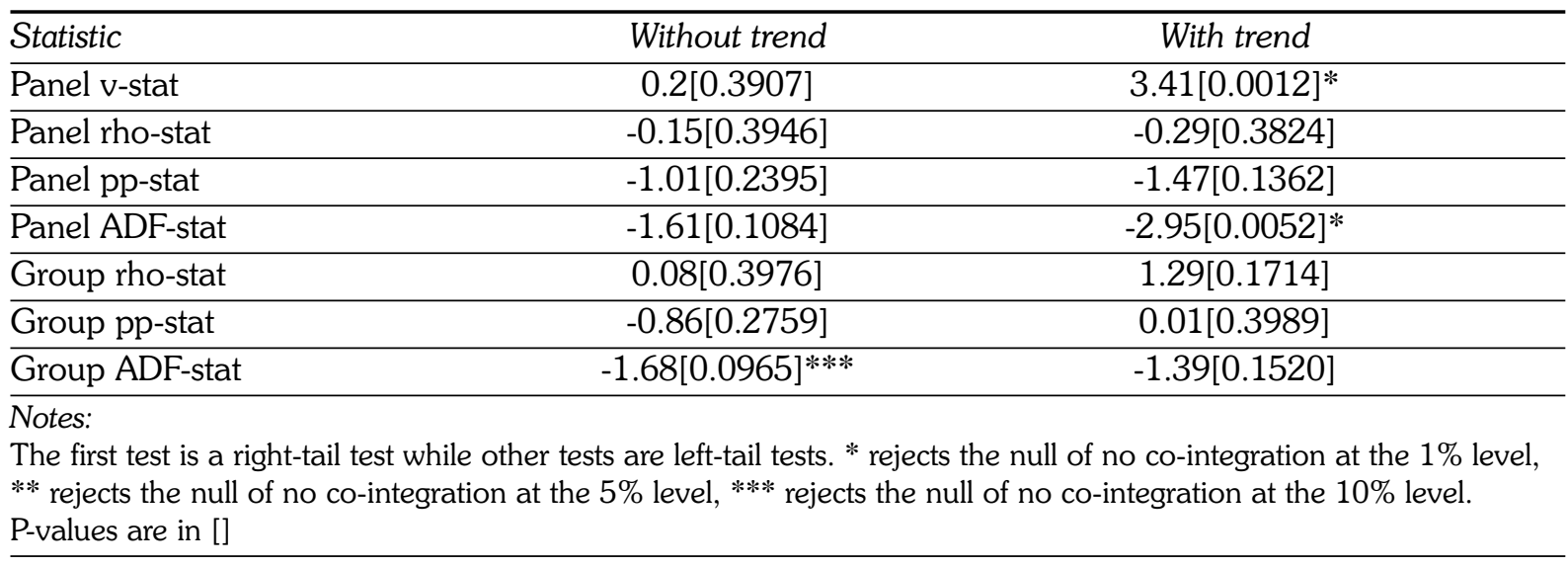


in first differences. We can then conclude that both variables are integrated of order one and we can proceed to the panel co-integration test.

The results of the panel co-integration test are presented in Table 2. Except for the panel v-statistic and panel ADF-statistic with trend, all other statistics do not reject the null of no co-integration. Since the majority of the test statistics do not show any evidence of co-integration, we conclude that energy consumption and real GDP are not co-integrated and so do not have a stable long-run relationship.

The fact that we did not find co-integration between energy consumption and real GDP does not mean that causality does not exist between them. Toda and Phillips (1993) show that if variables are $\mathrm{I}(1)$ but not co-integrated, causality can still exist between them. Granger causality tests will proceed by estimating vector auto regressions (VARs) but the error correction terms will be excluded. This implies that only short-run causality tests can be obtained. We proceed to conduct causality tests between energy consumption and real GDP by making use of the Hurlin and Venet methodology. The equations to be estimated will then take the form below:

$$
\begin{aligned}
& \Delta L E C_{i t}=\phi_{1}+\sum_{j=1}^{k} \chi_{1 j} \Delta L E C_{i t-j}+\sum_{j=1}^{k} \psi_{1 j} \Delta L Y_{i t-j}+\varepsilon_{1 t} \\
& \Delta L Y_{i t}=\phi_{2}+\sum_{j=1}^{k} \chi_{2 j} \Delta L E C_{i t-j}+\sum_{j=1}^{k} \psi_{2 j} \Delta L Y_{i t-j}+\varepsilon_{2 t}
\end{aligned}
$$

The hypothesis to be tested in equations 5 and 6 are as follows: we test the null hypothesis of no causality from energy consumption to economic growth by $\mathrm{H}_{0}$ : $\square_{2 \mathrm{j}}=0$ and acceptance of $\mathrm{H}_{0}$ implies that energy consumption does not cause economic growth. We test the null hypothesis of no causality from economic growth to energy consumption using $\mathrm{H}_{0}: \Psi_{1 \mathrm{j}}=0$, and acceptance of $\mathrm{H}_{0}$ implies that economic growth does not cause energy consumption.

The results of panel causality tests are presented in Tables 3 and 4. The first stage of the Hurlin and Venet (2001) panel causality test is the Homogenous Non Causality Test and this is presented in Table 3. The upper part of the table tests the hypothesis that energy does not cause economic growth and homogenous non causality hypothesis is rejected at lags 2 and 3 implying that energy consumption granger causes economic growth for at least one member of the panel. A similar conclusion can be drawn from the bottom part of Table 3 where also at lags 2 and 3 , we find that economic growth granger causes energy consumption for at least one member of the panel. The implication of this finding is that for at least one member of the panel there is bi-directional causality between energy consumption and economic growth.

Table 3: Panel homogenous non causality tests

\begin{tabular}{lc}
\hline$H_{0}: L E C$ does not Granger cause $L Y$ \\
\hline Lags & $F_{\text {hnc }}$ \\
\hline 1 & 0.52 \\
\hline 2 & $1.66^{* *}$ \\
\hline 3 & $3.36^{*}$ \\
\hline
\end{tabular}

\begin{tabular}{lc}
\hline \multicolumn{2}{l}{$:$ LY does not Granger cause LEC } \\
\hline Lags & $F_{\text {hnc }}$ \\
\hline 1 & 1.59 \\
\hline 2 & $3.26^{*}$ \\
\hline 3 & $2.90^{*}$ \\
\hline
\end{tabular}

Note:

* indicates statistical significance at the $1 \%$ level,

** indicates statistical significance at the $5 \%$ level.

Rejection of the homogenous non causality hypothesis means that we can go on to the next stage of the Hurlin and Venet test which is to test for homogenous causality across all members. The results of panel homogenous causality tests are presented in Table 4 and the hypothesis that causality is homogenous across all members of the panel is accepted. We find that causality runs both from energy consumption to economic growth, and from economic growth to energy consumption. Our results therefore support the feedback hypothesis.

Table 4: Panel homogenous causality tests

\begin{tabular}{|c|c|}
\hline \multicolumn{2}{|c|}{$H_{0}: L Y$ Granger causes LEC } \\
\hline Lags & $F_{h c}$ \\
\hline 1 & 0.02 \\
\hline$\overline{2}$ & 0.02 \\
\hline$\overline{3}$ & 0.01 \\
\hline $\begin{array}{l}\text { Note: } \\
* \text { indic } \\
\text { ** ind }\end{array}$ & $\begin{array}{l}\text { ace at the } 1 \% \text { level, } \\
\text { ance at the } 5 \% \text { level. }\end{array}$ \\
\hline
\end{tabular}

\begin{tabular}{lc}
\hline HO: LEC Granger causes $L Y$ & \\
\hline Lags & $F_{h c}$ \\
\hline 1 & 0.14 \\
\hline 2 & 0.08 \\
\hline 3 & 0.09 \\
\hline
\end{tabular}

\section{Conclusion}

This paper conducted an empirical investigation of the causality between energy consumption and real GDP using data for 14 Sub-Sahara African countries for the period $1971-2004$. We made use of panel unit root and co-integration tests to address the low power criticism of single country tests and 
panel causality tests were conducted so as to give more efficient results.

We did not find a stable long-run relationship between energy consumption and real GDP. The results of panel causality tests supported the feedback hypothesis as we found a bi-directional causal relationship between energy consumption and real GDP for all members of the panel. These results are not in line with previous studies on African countries. In the study by Wolde-Rufael (2005) bi-directional causality was found in 2 out of 19 countries. Akinlo (2008) found bi-directional causality in 3 out of 10 countries, while in Wolde-Rufael (2009) the feedback hypothesis was supported in 4 out of 17 countries. A possible explanation for the divergence between our results and those of previous studies is that estimates from time series studies could be unreliable and inconsistent because of the short time spans of the data (Lee, 2005; Narayan and Smyth, 2008).

\section{Note}

1. The countries have been selected based on data availability and are Benin, Cameroon, Congo Democratic Republic, Congo Republic, Cote d' Ivoire, Gabon, Ghana, Kenya, Nigeria, Senegal, South Africa, Togo, Zambia, Zimbabwe.

\section{References}

Akinlo, A.E. (2008). Energy Consumption and Economic Growth: Evidence from 11 Sub-Sahara African Countries, Energy Economics, 30, pp. 2391-2400.

Alam, M. S. (2006). Economic Growth with Energy, MPRA paper 1260, University Library of Munich, Germany.

Apergis, N. and Payne, J. E. (2009). Energy Consumption and Economic Growth in Central America: Evidence from a Panel Co-integration and Error Correction Model, Energy Economics, 31, pp. 211-216.

Cheng, B. S. and Lai, T. W. (1997). An Investigation of Co-integration and Causality between Energy Consumption and Economic Activity in Taiwan, Energy Economics, 19, pp. 435-444.

Choi, I. (2001). Unit Root Tests for Panel Data, Journal of International Money and Finance, 20, pp. 249-272.

Chontanawat, J. , Hunt, L. C. and Pierse, R. (2006). Causality between Energy Consumption and GDP: Evidence from 30 OECD and 78 Non-OECD Countries, Discussion Paper no. 113, Surrey Energy Economics Centre, Department of Economics, University of Surrey.

Ebohon, O. J. (1996). Energy, Economic Growth and causality in Developing Countries: A Case Study of Tanzania and Nigeria, Energy Policy, Vol. 24, No. 5, pp. 447-453.

Granger, C. W. J. (1988). Some Recent Developments in a Concept of Causality, Journal of Econometrics, 39 , pp. 199-211.
Hurlin, C. and Venet, B. (2001). Granger Causality Tests in Panel Data Models with Fixed Coefficients, Working Paper EURISCO NO 2001-09, Universite Paris Dauphine.

Im, K. S. , Pesaran, M. H. and Shin, Y. (2003). Testing Unit Roots in Heterogeneous Panels, Journal of Econometrics, 115, pp. 53-74.

International Energy Agency (2002). World Energy Outlook: Energy and Poverty, Paris.

Iwayemi, A. (1998). Energy Sector Development in Africa, a background paper prepared for the African Development Report 1998.

Jumbe, C. B. L. (2004). Electricity Consumption and GDP: Empirical Evidence from Malawi, Energy Economics, 26, pp. 61-68.

Karekezi, S. (2002). Poverty and Energy in Africa - A Brief Review, Energy Policy, 30, pp. 915-919.

Lee, C-C (2005). Energy Consumption and GDP in Developing Countries: A Co-integrated Panel Analysis, Energy Economics, 27, pp. 415-427.

Levin, A. , Lin, C. F. and Chu, C. S. J. (2002). Unit Root Tests in Panel Data: Asymptotic and Finite-Sample Properties, Journal of Econometrics, 108, pp. 1-24.

Maddala, G. S. and Wu, S. (1999). A Comparative Study of Unit Root Tests with Panel Data and a New Simple Test, Oxford Bulletin of Economics and Statistics, 61, pp. 621-652.

Masih, A. M. M. and Masih, R. (1996). Energy Consumption, Real Income and Temporal Causality: Results from a Multi-country Study Based on Co-integration and Error-correction Modelling Techniques, Energy Economics, 18, pp. 165-183.

Narayan, P. K. and Smyth, R. (2008). Energy Consumption and Real GDP in G7 Countries: New Evidence from Panel Co-integration with Structural breaks, Energy Economics, 30, pp. 2331-2341.

Oh, W. and Lee, K. (2004). Causal Relationship between Energy Consumption and GDP Revisited: The Case of Korea 1970-1999, Energy Economics, 26, pp. 5159.

Pedroni, P. (1999). Critical Values for Co-integration Tests in Heterogeneous Panels with Multiple Regressors, Oxford Bulletin of Economics and Statistics, 61, pp. 653-670.

Toda, H. Y. and Phillips, P. C. B. (1993). Vector Autoregressions and Causality, Econometrica, Vol. 61, No. 6, pp. 1367-1393.

Toman, M. and Jemelkova, B. (2003). Energy and Economic Development: An Assessment of the State of Knowledge, Discussion Paper no. 03-13, Washington D. C. : Resources for the Future.

Wolde-Rufael, Y. (2005). Energy Demand and Economic Growth: The African Experience, Journal of Policy Modelling, 27, pp. 891-903.

Wolde-Rufael, Y. (2009). Energy Consumption and Economic Growth: The Experience of African Countries Revisited, Energy Economics, 31, pp. 217224.

Received 28 November 2010; revised 2 July 2011 